\title{
Immunohistochemical evidences showing the presence of thymulin containing cells located in involuted thymus and in peripheral lymphoid organs
}

\author{
Hugo Folch', Juana V. Villegas², Víctor Leyan' ${ }^{1}$, Miguel Barría ${ }^{1}$, Gisela Eller ${ }^{3}$, and Patricio Esquivel ${ }^{1}$ \\ 1 Department of Immunology, Faculty of Medicine, Universidad Austral de Chile \\ 2 Department of Internal Medicine, Faculty of Medicine, Universidad de La Frontera \\ ${ }^{3}$ Department of Physiology, Faculty of Sciences, Pontificia Universidad Católica de Chile
}

\begin{abstract}
Thymulin is a well-characterized thymic hormone that exists as a nonapeptide coupled to equimolar amounts of $\mathrm{Zn}^{2+}$. Thymulin is known to have multiple biological roles, including $\mathrm{T}$ cell differentiation, immune regulation, and analgesic functions. It has been shown that thymulin is produced by the reticulo-epithelial cells of the thymus, and it circulates in the blood from the moment of birth, maintain its serum level until puberty diminishing thereafter in life. To study the localization of this hormone, we prepared polyclonal and monoclonal antibodies against the commercial peptide and utilized immunocytochemical techniques for visualization. The results indicate that thymulin stains the thymic reticular cells, the outer layers of Hassall's corpuscles and a large round cellular type, which is keratin-negative and does not show affinity for the common leukocyte antigen (CD-45). In mice, this thymulin-positive cell remains in the thymus throughout life and even appears in relatively increased numbers in old involuted thymi. It also appears in thymusdependent areas of the spleen and lymph nodes, demonstrating that at least one of the thymus cells containing this peptide can be found in peripheral lymphoid tissue.
\end{abstract}

Key terms: Thymulin, Facteur Thymique Serique, thymic hormones.

\section{INTRODUCTION}

The thymus is the central immunological organ where $\mathrm{T}$ cell differentiation and repertoire selection takes place. The thymus microenvironment, influenced by cellular and humoral signals, plays a central role in these events that shape the cellular immune response. Thymic hormones constitute an important part of the humoral thymus milieu, which contributes to $\mathrm{T}$ cell differentiation, and selection of $\mathrm{T}$ exportable cells to the periphery.

Thymic hormones are known to have pleiotropic roles within the thymic gland and in the periphery, but their immunological importance is not precisely understood. The reason for the lack of knowledge about the thymic factors functions may be, as Stutman proposed, due to research characterized by "passionate intuition" or the "mission oriented attitude" that dominated the field in early studies that sought solutions for health problems of immunodeficiency and autoimmunity (Stutman, 1983). This approach seems to continue to dominate the field of immunology, as well as other areas of biology research, emphasizing applications for medical problems in humans and economically important animals.

Thymic peptides have been purified and sequenced in the past, and even used in clinical trials. One of these thymic hormones is a well characterized nonapeptide originally isolated from serum by Bach and Dardenne (1972) and named Facteur Thymique Serique (FTS)(1973). The aminoacid sequence of this peptide is Glu-Ala-Lys-Ser-GlnGly-Gly-Ser-Asn and is produced by reticuloepithelial thymic cells (Dardenne et al., 1974). The biological activity of this thymic hormone is highly dependent on its molecular spatial conformation, which in turn depends on the metal element bound to its linear structure (Dardenne et al., 1982). It has been shown that the antigenic characteristics of this peptide and its capacity to induce differentiation in $\mathrm{T}$ cells depend on its equimolar association with $\mathrm{Zn}^{2+}$, but not with $\mathrm{Al}^{3+}$ or $\mathrm{Cu}^{2+}$ that can also bind (Gastinel et al, 1984; Cung et al, 1988).

The $\mathrm{Zn}^{2+}$-peptide complex with full biological activity is known as thymulin (Dardenne et al., 1982). At present we know that thymulin production is strongly influenced by the neuroendocrine system (Fabris and Mocchegiani, 1985; Dardenne et al., 1989) and that its serum level in humans and other mammals is age-dependent. (Bach and Dardenne, 1972; Bach and Dardenne, 1973; Consolini et al., 2000). Thymulin is capable of inducing some markers of $\mathrm{T}$ cell differentiation (Dardenne et al., 1978; Incefy et al., 1980), to restore some T cell functions (Bach et al., 1984), improve some endocrine parameters (Goya et al, 2007) and recently, it has become clear that this thymic factor possesses important antiinflammatory and analgesic properties (Safieh-Garabedian et al., 1982; Safieh-Garabedian et al., 1983; Dardenne et al., 2006).

In the present study, we describe the reactivity against different structures of lymphoid organs, of anti-synthetic thymulin polyclonal and monoclonal antibodies prepared in our laboratory. Results demonstrate that this thymic hormone is produced or accumulated, besides the reticuloepithelial thymic cells, in a particular large round cell present in the thymus and in peripheral lymphoid organs like spleen and lymph nodes. This cell, which we have designated as "C1", contains thymulin in cytoplasmic granules and is also present in the lymph nodes of nude and SCID mice, suggesting extrathymic production. 


\section{MATERIAL AND METHODS}

Obtaining lymphoid tissue

Lymphoid organs obtained from RK mice bred in our facility were used in the majority of the experiments shown here. According the needs of each experiment, Wistar rats were also used for immunization.

Animals were kept under standard conditions with food and water ad libitum. For some experiments, paraffinembedded lymphoid tissue of nude and SCID mice were obtained from the Center for Molecular Medicine and Infectious Disease at Virginia Tech., USA, and paraffinembedded normal human thymus was obtained from the Department of Pathology of the Hospital Regional de Valdivia, Chile.

\section{Preparation of antibodies against thymulin}

To produce rat polyclonal antibodies against thymulin, $2 \mathrm{mg}$ of the commercial peptide FTS was mixed with $6 \mathrm{mg}$ of Limulus polyphemus hemocyanin (LPH) (Sigma Chem. Co.) in a total volume of $1 \mathrm{ml} 0.1 \mathrm{M}, \mathrm{pH} 7.4$ phosphate buffer. Next, $25 \mu \mathrm{l}$ of $25 \%$ glutaraldehyde was added and the mixture was kept under constant agitation for $12 \mathrm{hrs}$. The conjugated material was dialyzed against a saline solution, the resulting volume was adjusted to $5 \mathrm{ml}$ and kept frozen until use.

To induce antibody production against the LPH-coupled peptide, the conjugate was emulsified with complete Freund's adjuvant and injected intradermally in multiple points in the dorsal region of rats. Each animal received 500 $\mathrm{ul}$ of the original conjugate. For the booster injection 3 weeks after the primary immunization, the same amount of the conjugate was emulsified in incomplete Freund's adjuvant and injected subcutaneously. After an additional 3 weeks, the rats received the same dose of antigen alone by intraperitoneal injection, and one week later the rats were bled. The serum was kept frozen until use.

For preparation of monoclonal antibodies, rats immunized as described above received a final booster given intravenously, and 3 days later spleen cells were obtained and fused with the plasmocytoma cell line NSO/2 following the procedure originally described by Koehler and Milstein (1975), with some modifications established in our laboratory previously described in detail (Villegas et al. 1991).

Specificity of antibodies against FTS and their capacity to bind thymulin

To test the capacity of the polyclonal and monoclonal antibodies to recognize FTS, the dot-immunobinding technique described by Hawkes et al. (1982) was used as an initial screening. Briefly, the synthetic FTS was conjugated to bovine seroalbumin (BSA) (Sigma Chem. Co, USA), the conjugate was adjusted to a concentration of $20 \mathrm{mg}$ per $\mathrm{ml}$, and $10 \mathrm{ml}$ aliquots of this peptide-carrier complex were seeded on nitrocellulose membranes (MFS, USA). The membranes were dried and subsequently blocked with $0.3 \%$ Tween 20 (Sigma Chem. Co.) in PBS for $45 \mathrm{~min}$ at $37{ }^{\circ} \mathrm{C}$. Next, the nitrocellulose membranes were incubated for $4 \mathrm{hrs}$ at $37{ }^{\circ} \mathrm{C}$ with dilutions of polyclonal rat antibodies or with non-diluted hybridoma supernatants. The membranes were washed three times, incubated with a rabbit anti-rat immunoglobulin produced in our laboratory, and then incubated with the PAP complex. After thorough washing, membrane reactions were visualized by incubation for 10 min with a saline solution containing $0.5 \mathrm{mg}$ diaminobencidine (DAB, Sigma Chem. Co.) and $0.03 \%$ of $\mathrm{H}_{2} \mathrm{O}_{2}$ (Farmoquímica del Pacífico S.A.). The enzymatic reaction was stopped with distilled water. In all experiments, appropriate positive and negative controls were included. To further determine if the selected hybridoma supernatants secreted antibodies able to recognize thymulin in situ, all dot immunobinding-positive supernatants were tested by immunocytochemistry using human thymus histological sections following the procedure described here.

\section{Histology and immunocytochemistry}

The tissue samples were immersed in Bouin's fixative, embedded in histological paraffin and cut into 6-mm sections, unless otherwise noted. Histological sections were stained with hematoxylin-eosin or processed for immunocytochemistry. The unlabeled enzyme immunocytochemistry method of peroxidase antiperoxidase (PAP) described by Sternberger (1979) was used throughout. Several primary antibodies were tested to characterize thymulin-containing cells. For this purpose, tissue sections were incubated with polyclonal rat or monoclonal rat anti-FTS primary antibodies overnight in a humid chamber at room temperature. In some experiments, rabbit anti-bovine cytokeratin or anti-human neuron specific enolase (Dako Corporation) were used. Primary antibodies were always diluted in $0.05 \mathrm{M}$ tris buffer, $\mathrm{pH} 7.8$. After incubation, tissue sections were extensively washed with phosphate buffer saline (PBS) and incubated for 30 min with the secondary antibody, next the sections were washed and the PAP complex was added. When the primary antibody was rat monoclonal or polyclonal immunoglobulin, we used a monoclonal rat PAP prepared according to Mason et al. (1982) and described elsewhere (Villegas et al., 1991). After incubation for 30 min with PAP, the sections were washed, and the reaction was revealed with a solution containing $0.2 \%$ of $3,3^{\prime}$ diaminobenzidine tetrahydrochloride (DAB, Sigma Chem. Co.) in the presence of $0.007 \% \mathrm{H}_{2} \mathrm{O}_{2}$ (Merck) for $15 \mathrm{~min}$ at room temperature. After incubation in $\mathrm{DAB}$, the sections were washed in distilled water, dehydrated, cleared with xylene and mounted with a coverslip.

In some experiments, monoclonal mouse anti-human CD45, anti-human CD15, anti-human cromogranin A, and anti-low molecular weight cytokeratin 8 (Dako Corporation), were used, followed by peroxidase conjugated rabbit antimouse immunoglobulin (Dako Corporation). The reaction was visualized as described above.

For immunoelectron microscopy, the tissue was immersed in Bouin's fixative and then in $1 \% \mathrm{OsO} 4$ in $0.2 \mathrm{M}$, pH 7.4 phosphate buffer. The tissue was then dehydrated with increasing concentrations of ethanol, ending with pure acetone, and embedded in an epon-araldite mixture. Next, the immunoglobulin-gold technique was used to localize the thymulin containing structures. For this purpose, ultrathin sections were sequentially incubated with monoclonal rat anti-FTS 4F11 for $18 \mathrm{hrs}$, rabbit anti-rat immunoglobulin for 
$30 \mathrm{~min}$, and gold conjugated anti-rabbit immunoglobulin (20 $\mathrm{nm}$ ) (Polysciences Inc.) for $30 \mathrm{~min}$. Finally, the sections were stained with uranil acetate and lead citrate and then examined in a Phillips 300 electron microscope.

\section{RESULTS}

Polyclonal and monoclonal antibodies prepared against the synthetic FTS peptide recognize the hormone in the dot immunobinding technique, and some of them recognize thymulin in situ in the thymus gland

All the polyclonal antibodies obtained after immunization of rats with the peptide FTS reacted with thymic structures in a similar way. However, with the monoclonal antibodies, not all hybridomas whose supernatant gave a positive reaction against the synthetic thymic peptide through the dot immunobinding technique were able to detect thymulin in human thymus tissue. The most efficient monoclonal antibody obtained was produced from the 4F11 hybridoma. This hybridoma secretes rat IgM antibody that labels the same structures as the polyclonal antibodies. To study the distribution and the appearance of the cells that contain thymulin, sections of human thymic gland sections were examined. It is clear that both the monoclonal antibody $4 \mathrm{~F} 11$ and polyclonal antibody prepared against FTS bind to thymus reticulo-epithelial cells. These cells are found in the thymus medullar area and at the peripheral layers of Hassall's corpuscles. In addition, in all cases, a strongly stained large round cell (20-30 $\mathrm{mm}$ diameter) that we designated as the "C1 cell" was present (Fig. 1).

Binding capacity of antibody $4 F 11$ with its antigen is abrogated after incubation with thymulin or serum from young animals

In order to further test the specificity of our anti-FTS monoclonal antibody 4F11, $1 \mathrm{ml}$ of the supernatant of clone 4F11 was incubated with $100 \mathrm{ng}$ of thymulin or $1 \mathrm{~mL}$ of young mice serum. The results showed that in both cases, the binding capacity of antibody $4 \mathrm{~F} 11$ to nitrocellulose membrane containing the conjugated peptide or to human thymus tissue sections was completely abrogated.

\section{Characterization of the thymulin-positive " $\mathrm{C} 1$ " cell}

Reticulo-epithelial cells and Hassall's corpuscles were also labeled with anti-keratin antibodies, confirming their epithelial nature. However, the C1 cell, which reacts strongly
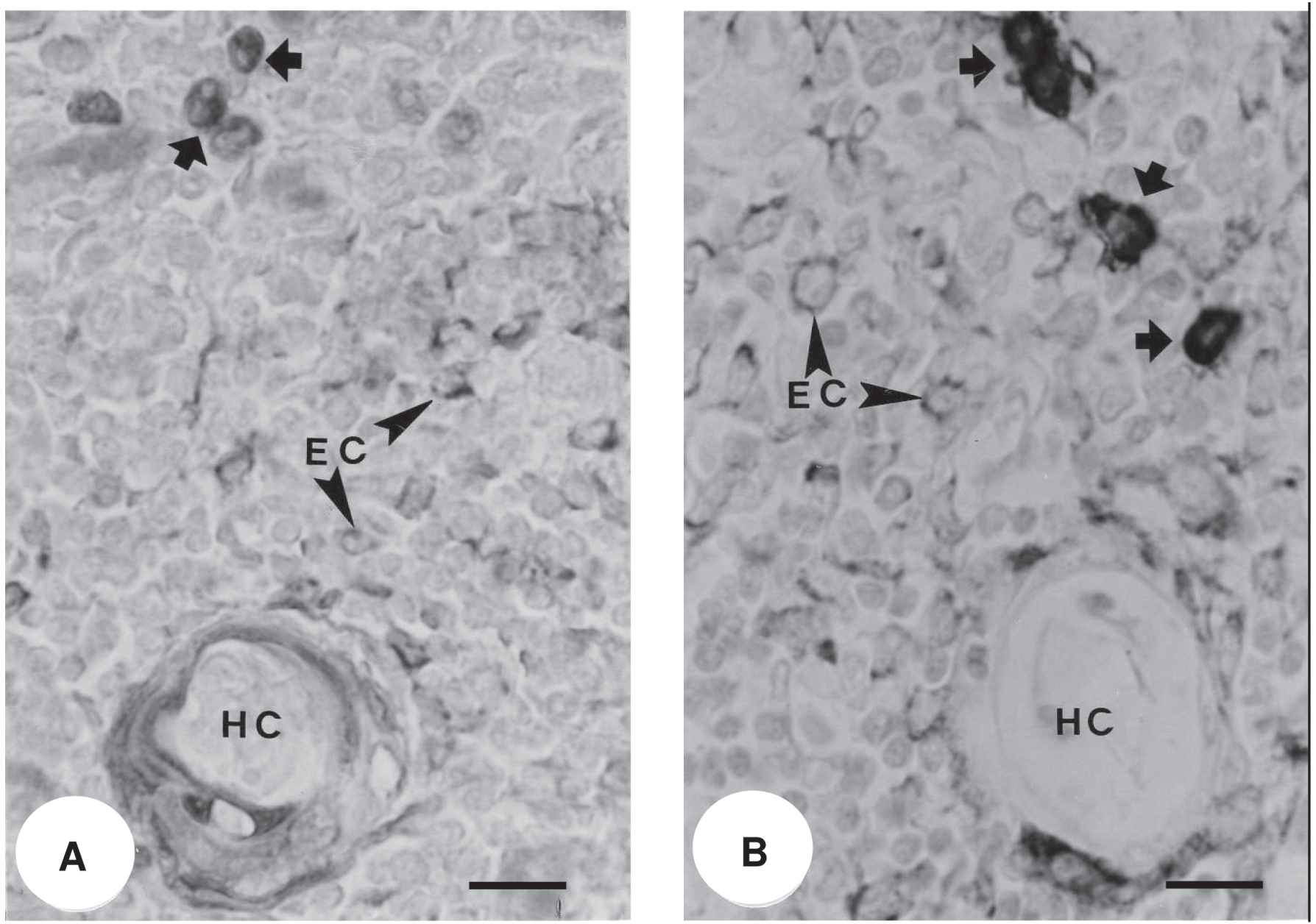

Figure 1: Human thymus immunostained with polyclonal anti-FTS antibodies prepared in rat (A), compared with the rat anti-FTS monoclonal antibody 4F11 (C). In all cases the antibodies strongly labeled the C1 cells (arrows), the epithelioreticular cells (EC), and the external epithelial cells of the Hassall's corpuscle (HC). Bar $=60 \mu \mathrm{m}$ 
with all polyclonal and monoclonal anti-thymulin antibodies tested, does not bind anti-keratin antibodies and is negative for CD-45 (Fig. 2). Therefore, the C1 cell appears to not be from an epithelial or leukocyte origin. This cell type was also negative for chromagranine $A$, a member of the secretogranin/chromoganin class of proteins that are frequently present in a wide variety of neurons and endocrine cells. Additionally, the $\mathrm{C} 1$ cell did not react with antibodies against neuron-specific enolase, ruling out a possible endocrine or neural origin.

\section{Ultrastructural examination of the $\mathrm{C} 1$ cell}

To further study the $\mathrm{C} 1$ cell, thin sections of mice thymus were prepared and immunostained with antibody 4F11. The C1 cell shows cytoplasmatic granules where the 4F11 reactive molecule is located (Fig. 3). This observation was corroborated by an ultrastructural study in which ultrathin sections of the thymus gland were incubated with the 4F11 antibody followed by gold-labeled rabbit anti-rat immunoglobulin. The results show that the anti-thymulin monoclonal antibody recognizes and binds to electrodense cytoplasmic granules (Fig. 3, insert).

In old mice lacking circulating thymulin, C1 cells are present at a higher density in the thymus

Interestingly, thymi of old mice without detectable levels of circulating thymulin show the presence of $\mathrm{C} 1$ thymulinpositive cells (Fig. 4). A low magnification section of a young mouse thymus shows the $\mathrm{C} 1$ cell with a distribution in the medullar or cortico-medullar area (A). In contrast, in the old thymus where the thymic cortex is absent, increased numbers of the $\mathrm{C} 1$ cells are distributed in the whole tissue section (B).
Presence of the thymulin-positive $\mathrm{C} 1$ cell in the spleen and lymph nodes of normal mice as well as in lymphoid organs of athymic mice

A cell with characteristics similar to the thymic C1 cell may be found in spleen and lymph nodes. In the spleen it appears irregularly distributed, usually in small groups in the white pulp, and in the lymph node it can be found in the paracortical zone, among the lymphoid follicles, and in the medullar cords. In figure 5 we show spleen and lymph node sections of a normal two-month-old mouse stained with antibody 4F11, followed by mouse anti-rat immunoglobulin and PAP complex. To our surprise, similar cells appear when spleen or lymph nodes from nude or SCID mice were tested with the 4F11 antibody (Fig. 6)

\section{DISCUSSION}

As we have reported here, not all the monoclonal antibodies prepared in our laboratory react against the FTS in the dot assay, recognize thymulin in situ. This may be due to several causes that are not mutually exclusive, for example, the binding process of the peptide with the carrier used in immunization or in the dot detection system may change its spatial molecular configuration. Other possible causes of the spatial molecular changes in the peptide are the multiple possibilities of combinations that this peptide can have with different metals and the different peptide/metal ratio binding that, as has been described, change the molecular conformation of the peptide, its antigenicity, and biological activity (Gastinel et al., 1984; Dardenne et al., 1982; Cung et al., 1988). This raises the possibility that we are not dealing with one molecule of active hormone but with several related molecular entities. To make the scenario even more complex, the molecules that we are dealing with may have different biological functions.
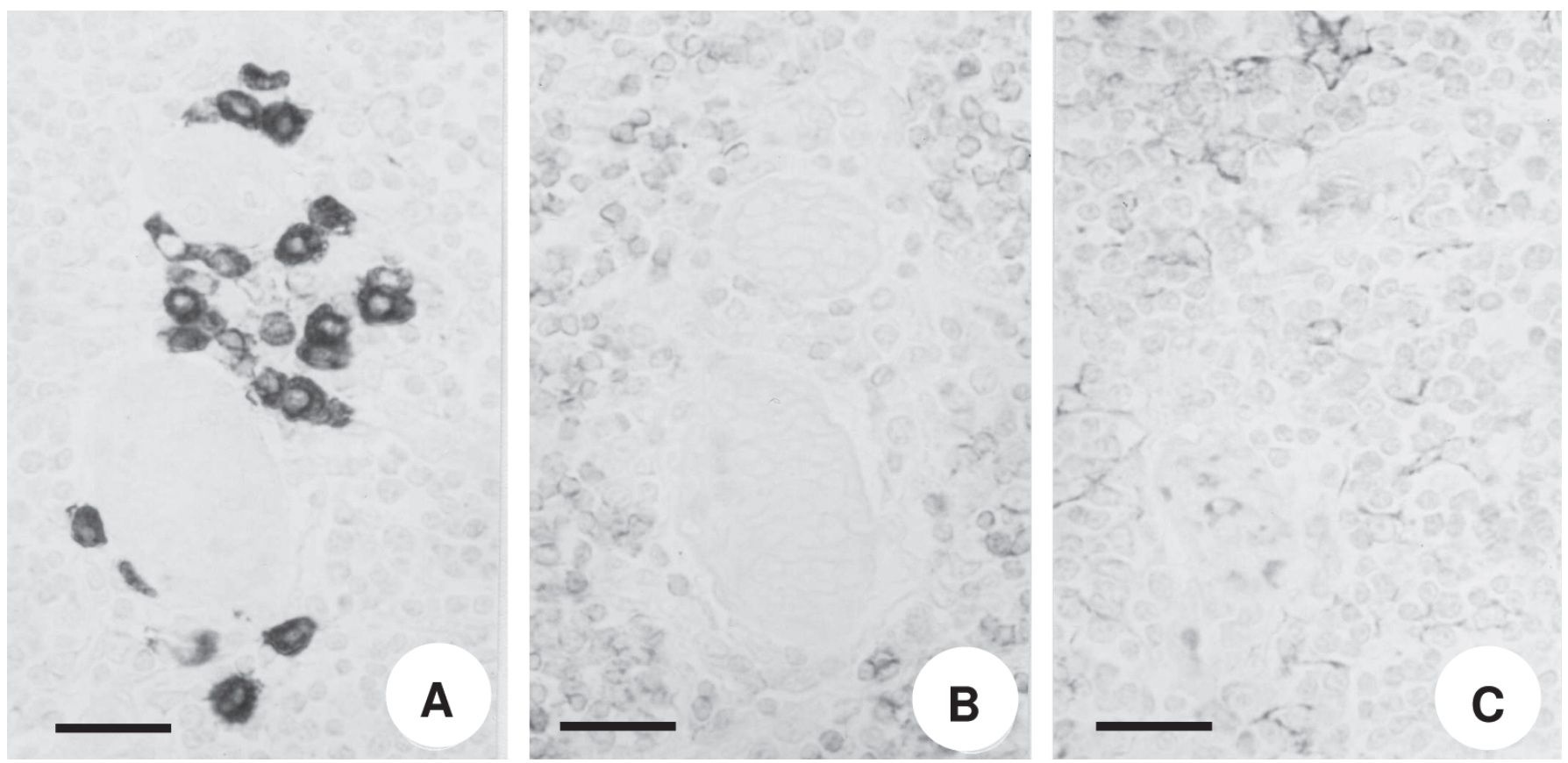

Figure 2: Human thymus showing $\mathrm{C} 1$ cells immunostained with monoclonal antibody $4 \mathrm{~F} 11$ located around vascular structures (A). Tissue sections of the same area were stained with monoclonal antibodies anti-CD45 (B) and anti-keratin 8 (C). Bar $=120 \mu \mathrm{m}$ 


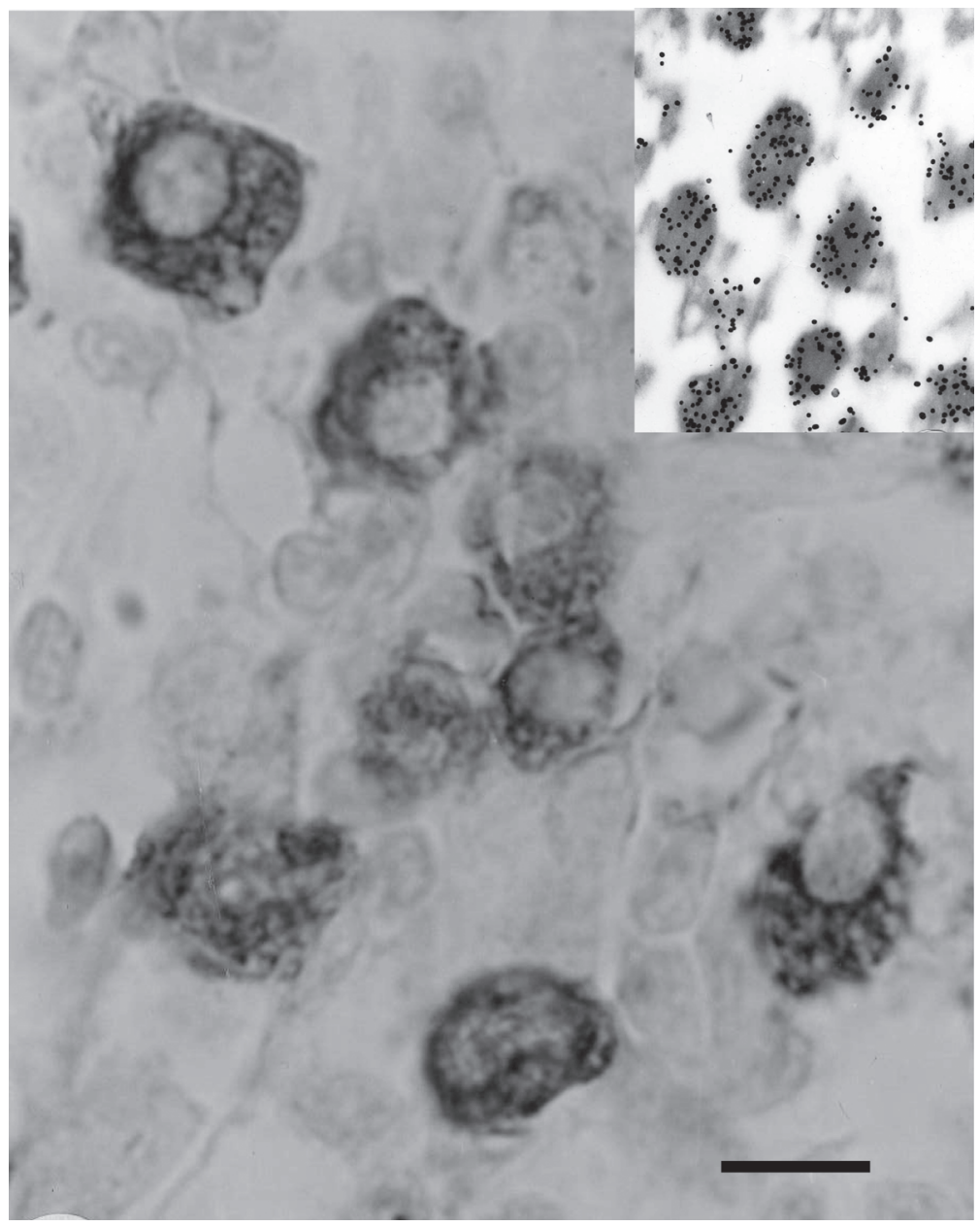

Figure 3: Thymus thin section showing a $\mathrm{C} 1$ cell containing thymulin-positive cytoplasmatic granules stained with the rat monoclonal anti-FTS antibody. Insert show the same granules detected by electron microscopy with immunoglobulin gold $(20 \mathrm{~nm})$. Bar $=30 \mu \mathrm{m}$
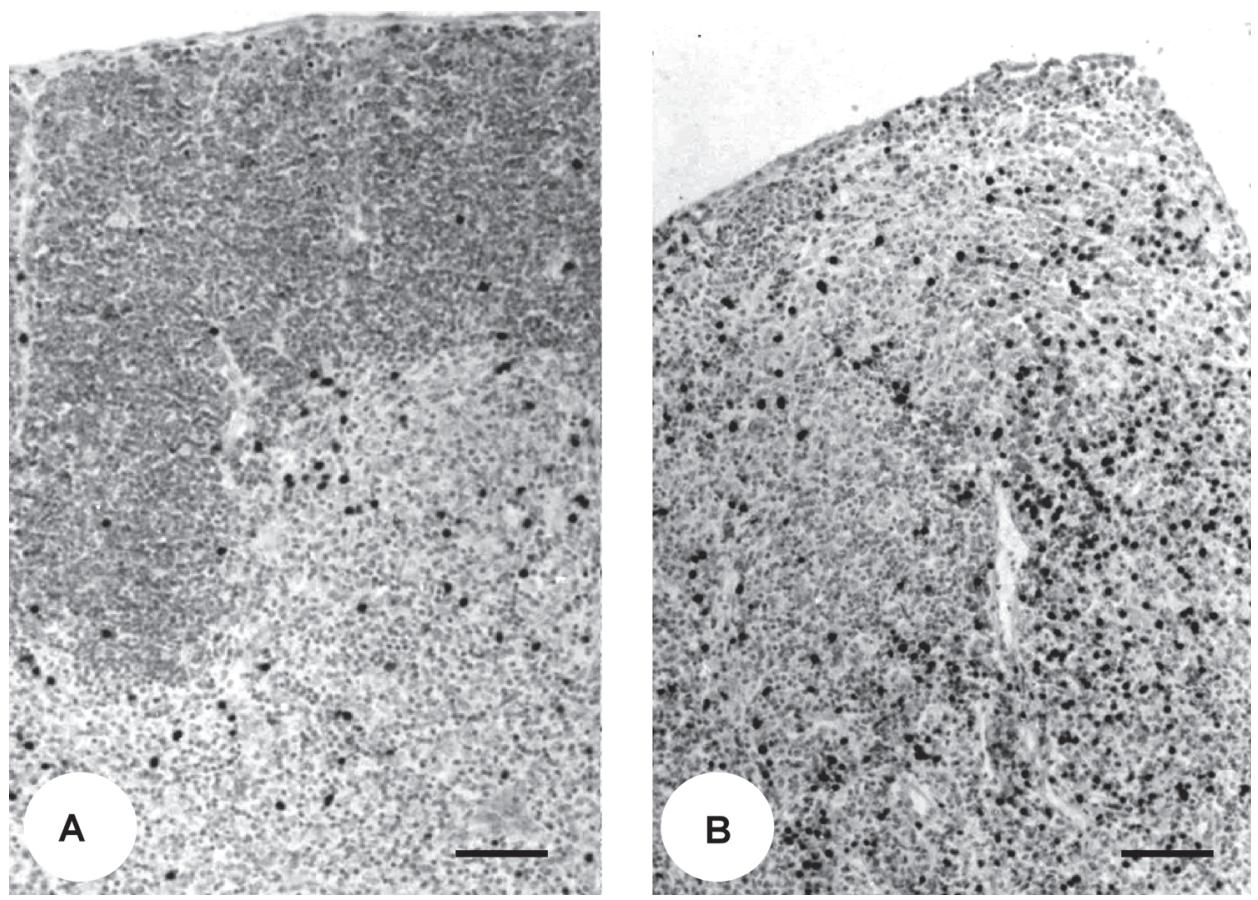

Figure 4: Thymus from young adult mice (A) and from ten month old mice (B) stained with anti-thymulin antibody 4F11. Bar $=$ $300 \mu \mathrm{m}$ 

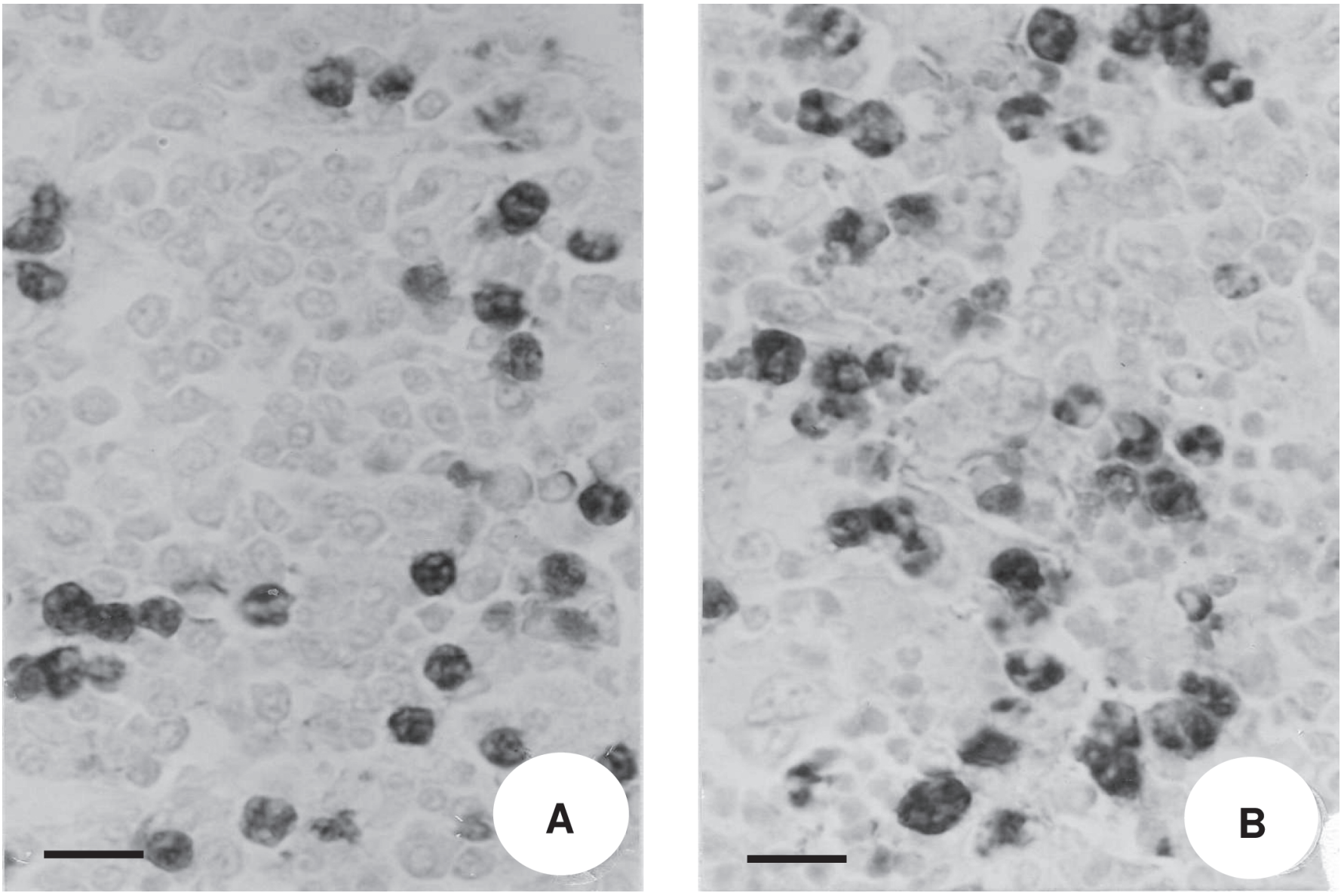

Figure 5: Spleen (A) and lymph node (B) sections of normal RK mice, stained with anti-thymulin antibody $4 \mathrm{~F} 11$. Bar $=60 \mu \mathrm{m}$
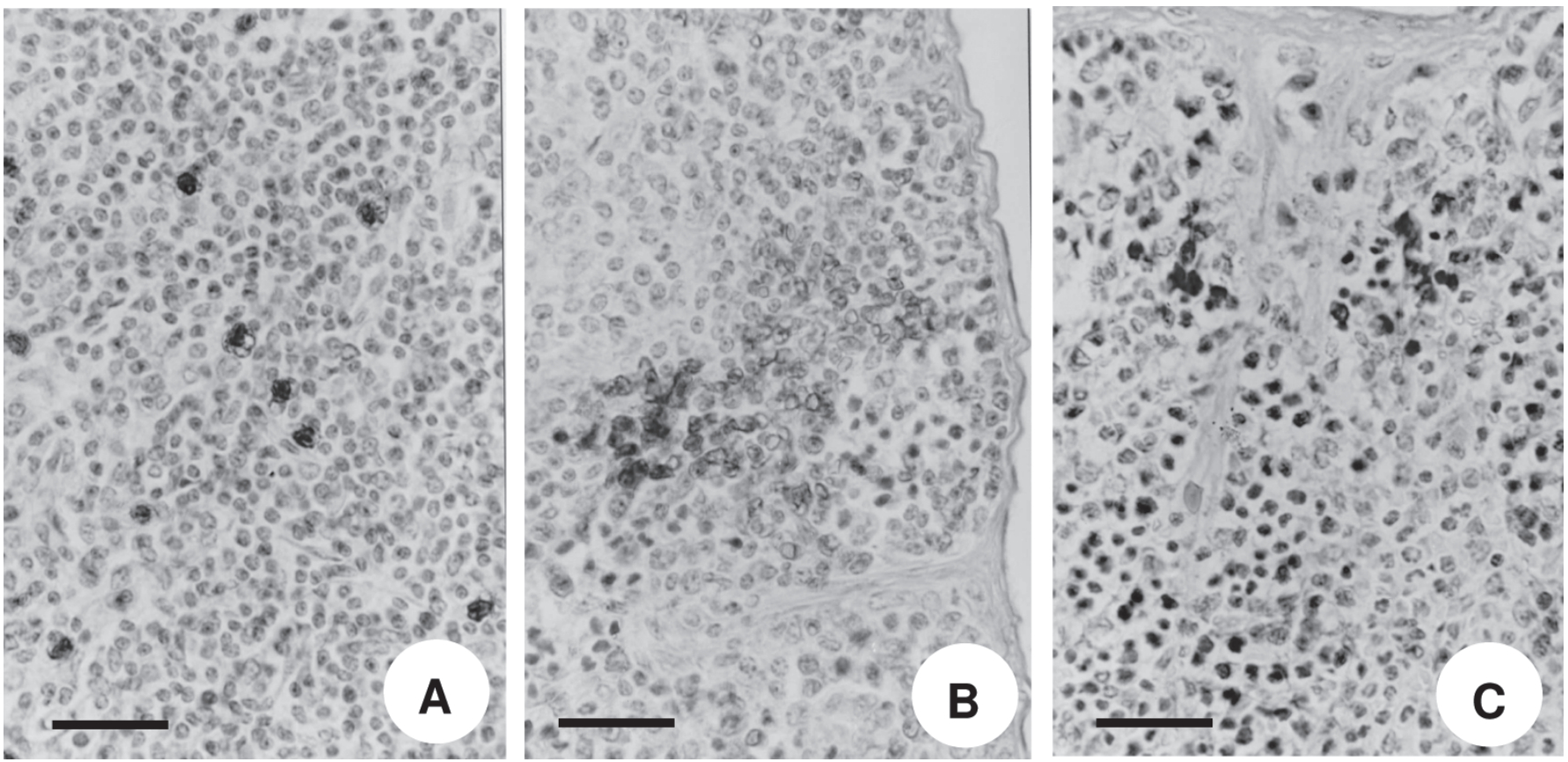

Figure 6: Spleen (A) and lymph node (B) of nude athymic mice and lymph node of SCID mice stained with anti-thymulin antibody $4 \mathrm{~F} 11 . \mathrm{Bar}=150 \mu \mathrm{m}$ 
The selected monoclonal antibodies prepared here were able to recognize the antigen coupled to different carriers (results not shown) or thymulin in situ, as did polyclonal antibodies. One of these monoclonals is the 4F11 antibody, which was tested in several ways for specificity and was selected for its capacity to recognize the synthetic peptide coupled to BSA and bind with nitrocellulose membrane and in situ in human thymus sections. These capacities disappeared when it was incubated with a commercial synthetic peptide or mouse serum. In this case, the activity of the antibody was efficiently absorbed by serum obtained from young healthy mice, and to our surprise, was also absorbed by sera from old or thymectomized mice, although with less efficiency, indicating that some molecule crossreacting with thymulin or thymulin itself is present in low quantities in these animals. We have to remember that sera of old and thymectomized mice are negative to the Rosette test, which is the classical way to evaluate this thymic hormone. On the other hand, we can assume that the specificity of this antibody is thymulin, since it can abrogate the capacity of young serum to give a positive result to the Rosettte test (results not shown). In the thymus, it is clear that antibody $4 \mathrm{~F} 11$ and the polyclonal antibodies prepared in our laboratory, label at least three structures: endothelialreticular cells, Hassall's corpuscles and the C1 cells. The first two structures can easily be identified by classical histology, as well as by the fact that both react with antibodies against keratin. The case of the C1 cell, described in the Results Section, is different in that it does not bind anti-keratin antibodies. One interpretation of this is that this cell does not belong to the endodermic reticulo-epithelial cells that constitute the thymus stroma. Another explanation for the lack of reactivity with anti-keratin immunoglobulins is that this cell belongs to reticulo-epithelial cells that at a given stage of the cell cycle are deprived of keratin antigen. The latter explanation is difficult to accept since, as we show also here, these cells are present in lymphoid peripheral tissue, even in athymic mice. At an ultra structural level, the C1 positive cell contains large granules that are not normally present in reticular thymic cells. Unfortunately, Bouin is the best fixative to preserve the antigenicity of thymulin in our hands, but it is poor for maintaining the integrity of the tissue at the ultrastructural level, which makes further ultrastructural studies difficult.

Another aspect shown here that has not been reported in the literature is that in aged animals we found normal reactivity of thymic reticulo-epithelial cells with polyclonal and the monoclonal antibody 4F11. Moreover, we show here an important increase in the number of $\mathrm{C} 1$ cells in the old thymus, which could be due to a concentration of this cell as result of the involution of the lymphoid part of the thymic gland. Surprisingly, the C1-containing thymulin cell was also found in thymus dependent areas of spleen and lymph nodes. This is also contrary to the findings of Dardenne's group (Berrih, 1984) and contrary to the dogma that says that thymulin is "exclusively produced in the thymus gland" (Dardenne et al., 1974). In relation to this, we cannot rule out the possibility that these C1-like peripheral cells may only be "storing" this thymic peptide. On the other hand, other authors have already described the existence of peripheral cells that bind anti-thymulin antibodies, Kato, for example, showed that epithelial cells react in the periphery with anti- thymulin immunoglobulins (1982). The hypothetic thymulin storing role of this peripheral C1-like cell is hard to accept after observing that the spleen and lymph node of athymic nude mice also present these cells, opening the possibility that thymulin can be produced in the periphery, and that even in small quantities, may contribute to peripheral $\mathrm{T}$ cell differentiation, as has been suggested before (Dardenne et al.,1978; Incefy et al., 1980). This possibility is reinforced by preliminary results not shown here, where we found an abnormally high number of this cell in the lymph node of a mycosis fungoide patient. These findings almost perfectly match with the fact that the serum level of thymulin increases in this disease (Incefy et al., 1980), giving a possible explanation for the characteristic excessive $\mathrm{T}$ cell proliferation. A second possible role of thymulin generated outside of thymus may be its contribution to the extrathymic $\mathrm{T}$ cell generation pathway that has been postulated for many years (MacDonald et al., 1981; Lawetsky et al., 1988 ) and we know now that it exists (Lake et al., 1991), giving rise to a definitive $\mathrm{T}$ cell population with different attributes compared to the one generated in the classical thymic pathway (Blais et al., 2008).

The results shown here were obtained with appropriate techniques to avoid possible false positives, and with tissue samples that facilitate the interpretation of the results. Because the majority of the tissue used in the histology studies was obtained from mice and the antibodies against thymulin were obtained from rats, the use of a second commercial antibody against rat immunoglobulin prepared in goat or rabbit is likely to react against mouse immunoglobulins, giving positively labeled B cells. To avoid this inconvenience, we prepared mouse immune serum against rat immunoglobulin, which was used as a second antibody followed by monoclonal rat PAP already described elsewhere (Villegas et al., 1991). On the other hand, for in situ tests of monoclonal antibodies secreted by the different clones, we used sections of human thymus since mice and other experimental animals lack well-developed thymic Hassall's corpuscles, a classical structure that is known to bind anti-thymulin antibodies (Jambon et al., 1981).

In summary, our results show that the thymic peptide originally described by Bach may adopt different molecular configurations with different antigenic characteristics and possibly different biological activities. Additionally, thymulin appears to be produced, or at least stored, outside the thymus. We are aware that some of these results are contrary to the classical literature, but as Professor Hoecker said, "once you are sure of your data, you must publish it is no matter the reaction of the scientific community." In any case, we offer our antibody 4F11 to interested researchers.

\section{REFERENCES}

BACH JF, DARDENNE M (1972) Thymus dependency of rosette forming cells. Evidence for a circulating thymic hormone. Transplant Proc 4: 345-349.

BACH JF, DARDENNE M (1973) Studies on thymus products. II. Demonstration and characterization of a circulating thymic hormone. Inmunology 25: 353-366.

BACH J, DARDENNE M, GOLDSTEIN AL (1984) Thymic hormones and lymphokines. In: GOLDSTEIN AL (ed) Clinical Aspects of thymulin (FTS). New York: Plenum Press. pp 593-600.

BERRIH S, SAVINO W, AZOULAY M, DARDENNE M, BACH JF (1984) Production of anti-thymulin (FTS) monoclonal antibodies by 
immunization against human thymic epithelial cells. J Histochem Cytochem 32: 432-438.

BLAIS ME, BROCHU S, GIROUX M, BELANGER MP, DULUDE G, SEKALY RP, PERREAULT C (2008) Why T cells of thymic versus extrathymic origin are functionally different. J Immunol 180: 22992312.

CONSOLINI R, LEGITIMO A, CALLERI A, MILANI M (2000) Distribution of age-related thymulin titres in normal subjects through the course of life. Clin Exp Immunol 121:444-447.

CUNG MT, MARRAUD M, LEFRANCIER P, DARDENNE M, BACH JF, LAUSSAC JP (1988) NMR study of a lymphocyte differentiating thymic factor. J Biol Chem 263: 5574-5580.

DARDENNE M, CHARREIRE J, BACH JF (1978) Alterations in thymocyte surface markers after in vivo treatment by serum thymic factor. Cell Immunol 39:47-54.

DARDENNE M, NABARRA B, LEFRANCIER P (1982) Contribution of zinc and other metals to the biological activity of serum thymic factor (FTS). Proc Natl Acad Sci USA 79: 5370-5373.

DARDENNE, M, PAPIERNIK M, BACH JF, STUTMAN O (1974) Studies on thymus products. III. Epithelial origin of the serum thymic factor. Immunology 27: 299-304.

DARDENNE M, SAADE N, SAFIEH-GARABEDIAN B (2006). Role of thymulin or its analogue as a new analgesic molecule. Ann N Y Acad Sci 1088: 153-63.

DARDENNE M, SAVINO $\mathrm{W}$, GAGNERAULT MC, ITOH T, BACH JF (1989) Neuroendocrine control of thymic hormonal production. I. Prolactin stimulates in vivo and in vitro the production of thymulin by human and murine thymic epithelial cells. Endocrinology 125:312.

FABRIS N, MOCCHEGIANI E (1985) Endocrine control of thymic serum factor production in young adult and old mice. Cell Immunol 91:325335.

GASTINEL LN, DARDENNE M, PLEAU JM, BACH JF (1984) Studies on the zinc-binding site to the serum thymic factor. Biochim Biophys Acta 797: 147-155.

GOYA RG, REGGIANI PC, VESENBECKH SM, PLÉAU JM, SOSA YE CÓNSOLE GM, SCHADE R, HENKLEIN P, DARDENNE M (2007) Thymulin gene therapy prevents the reduction in circulating gonadotropins induced by thymulin deficiency in mice. Am J Physiol Endocrinol Metab 293: E182-187.

HAWKES R, NIDAY E, GORDON J (1982) A dot-inmunobinding assay for monoclonal and other antibodies. Anal Biochem 119: 142-147.

INCEFY GS, MERTELSMANN R, YATA K, DARDENNE M, BACH JF, GOOD RA (1980) Induction of differentiation in human marrow $\mathrm{T}$ cell precursors by the synthetic serum thymic factor, FTS. Clin Exp Immunol 40: 396-406.
JAMBON B, MONTAGNE P, BENE MC, BRAYER MP, FAURE G, DUHEILLE J (1981) Immunohistologic localization of "facteur thymique sérique"(FTS) in human thymic epithelium. J Inmunol 127: 2055-2059.

KATO $\mathrm{K}$, IDEYAMA S, TAKAOKI M, SHINO A, YAKAUCHI M, KAKINUMA A (1981) Epithelial cell components immunoreact with antiserum thymic factor antibodies: possible association with intermediate-sized filaments. Cell 24: 885-895.

LAKE J P, PIERCE CW, KENNEDY JD (1991). T cell receptor expression by $\mathrm{T}$ cells that mature extrathymicaliy in numde mice. Cell Immunol 135: 259-265.

LAWETZKY A, HUNIG T (1988) Analysis of CD3 and antigen receptor expression on $\mathrm{T}$ cell subpopulations of aged athymic mice. Eur $\mathrm{J}$ Immunol 18:409-416.

MACDONALD HR, LEES RK, SORDAT B, ZAECH P, MARYANSKI JL, BRON C (1981) Age-associated increase in expression of the $T$ cell surface markers Thy-1, Lyt-1, and Lyt-2 in congenitally athymic (nu/ $\mathrm{nu})$ mice: analysis by flow microfluorometry. J Immunol 126: 865-870.

MASON DY, CORDELL JL, ABDULAZIZ Z, NAIEM M, BORDENAVE G (1982) Preparation of peroxidase: antiperoxidase (PAP) complexes for immunohistological labeling of monoclonal antibodies. J Histochem Cytochem 30:1114-1122.

REGGIANI PC, MOREL GR, CÓNSOLE GM, BARBEITO CG, RODRIGUEZ SA, BROWN OA, BELLINI MJ, PLÉAU JM, DARDENNE M, GOYA RG (2009) The thymus-neuroendocrine axis. Physiology, molecular biology, and therapeutic potential of the thymic peptide thymulin. Ann NY Acad Sci 1153: 98-106.

SAFIEH-GARABEDIAN B, DARDENNE M, PLEAU J-M, SAADE NE (2002) Potent analgesic and anti-inflammatory actions of a novel thymulin-related peptide in the rat. Br J Pharmacol 136: 947-955.

SAFIEH-GARABEDIAN B, OCHOA-CHAAR CI, POOLE S, MASSAAD CA, ATWEH SF, JABBUR SJ, SAADE NE (2003) Thymulin reverses inflammatory hyperalgesia and modulates the increased concentration of proinflammatory cytokines induced by i.c.v. endotoxin injection. Neuroscience 121: 865-873.

STERNBERGER LA, HARDY PH JR, CUCULIS JJ, MEYER HG (1970) The unlabeled antibody enzyme method of immunohistochemistry: preparation and properties of soluble antigen-antibody complex (horseradish peroxidase-antihorseradish peroxidase) and its use in identification of spirochetes. J Histochem Cytochem 18:315-333.

STUTMAN O (1983) Role of thymic hormones in T cell differentiation in J F BACH (ed) Clinics in Immunology and Allergy, London : W B Sounders. pp: 6-67.

VILLEGAS J, ELLER G, LEYÁN V, ESQUIVEL P, FOLCH H (1991) Preparación y caracterización de complejo peroxidasa-antiperoxidasa monoclonal. Arch Biol Med Exp 24: 61-66. 